\title{
The impact of minimum age of employment regulation on child labor and schooling
}

\author{
Eric V Edmonds ${ }^{1 *}$ and Maheshwor Shrestha ${ }^{2}$
}

\author{
* Correspondence: eric.v.edmonds@ \\ dartmouth.edu \\ ${ }^{1}$ Dartmouth College Department of \\ Economics. 6106 Rockefeller Hall. \\ Hanover, NH 03755, USA \\ Full list of author information is \\ available at the end of the article
}

\begin{abstract}
Promoting minimum age of employment regulation has been a centerpiece in child labor policy for the last 15 years. If enforced, minimum age regulation would change the age profile of paid child employment. Using micro-data from 59 mostly low-income countries, we observe that age can explain less than one percent of the variation in child participation in paid employment. In contrast, child-invariant household attributes account for 63 percent of the variation in participation in paid employment. While age may explain little of the variation in paid employment, minimum age of employment regulation could simultaneously impact time allocation. We do not observe evidence consistent with enforcement of minimum age regulation in any country examined, although light work regulation appears to have been enforced in one country.

JEL Codes: J22, O15, J88, K42
\end{abstract}

\section{Introduction}

Labor laws and regulation are the primary instruments used by many countries to combat child labor. The last 15 years has seen an enormous surge in these laws as international pressure has encouraged low income countries to sign international conventions related to the prohibition of child labor and to pass labor laws consistent with the principals of those conventions. Most countries now have laws in place that prohibit the economic activity of children below age 12 and regulate employment through age 17.

This paper considers the impact of laws that restrict the minimum age of employment on child labor and schooling. Such laws are principally directed at paid employment outside of the family. When enforced, they alter the age distribution and location of child employment. An upper bound on the importance of these laws in influencing the prevalence of child labor would attribute all of the age variation in work outside of the household to these laws. Of course, there are many reasons other than regulation that would lead time allocation to vary with age. Even so, using data from 59 countries included in rounds 2 and 3 of UNICEF's Multiple Indicator Cluster Survey, we observe that age accounts for little of the variation in paid employment outside of the home, schooling, or idleness. ${ }^{1}$ For example, age explains less than 0.5 percent of the variation in paid employment in the 29 African countries examined herein. The largest share of the variation in paid employment explained by age in Africa is 1.6 percent in Madagascar, where compulsory schooling and minimum age of employment regulations relax at the same age. In contrast, household characteristics such as income and parental background account for 67 percent of the variation in paid employment in our African data and 63 percent across 
all countries. These findings are consistent with the literature from high income countries that document an impact of minimum age of employment regulation and compulsory schooling laws on education but find the impact of these law changes to be modest compared to the secular trends (Moehling 1999, Lleras-Muney 2002, Goldin and Katz 2011).

Age may account for little of the variation in paid employment, but there is still scope for minimum age of employment regulation to influence time allocation. To examine this, we look for changes in time allocation at the minimum age of employment in each of the 59 countries separately and pooled. Our econometric approach is to compare the observed prevalence of paid employment at the minimum age of employment to what would be predicted based on an age trend estimated on the regulated (younger) ages. Our estimates of the impact of minimum age regulation are, in effect, estimates of the impact on paid employment of extending current minimum age regulations by one additional year, holding all prices fixed. Of course, this design does not inform the counterfactual of what employment would be in the absence of minimum age laws altogether.

In the pooled and weighted data from all 59 countries representing 158 million children, we find that paid employment increases by a statistically insignificant 0.7 percentage points, or 11 percent, at the minimum age of employment. When we look at each country separately as well as at all the different measures of time allocation available in our data, we are plagued by the multiple hypothesis problem and type I errors. We rely on economic theory to assess whether statistically significant changes stem from minimum age regulation. In the presence of competitive labor markets and working capital within the household, we show that binding minimum age of employment regulations shift child work to the family farm or business but have no effect on schooling. Our argument is based on three assumptions. First, child and adult labor are perfect substitutes subject to a productivity shifter ("the substitution axiom" in Basu and Van 1998). Second, the child's household can freely substitute adult and child labor between productive tasks inside the household, i.e. "non-saturation." Third, adult labor can move freely between the household and the labor market, i.e. "competitive adult labor markets."

According to this theory, the data will be consistent with binding minimum age of employment regulation when we observe increases in paid employment, decreases in work inside the household, and no change in schooling or idleness at the minimum age of employment. In the data, we observe increases in paid employment at the minimum age only in 4 of the 59 countries. We do not observe a significant or substantive decline in work inside the family at the minimum age in any of the countries. Hence, we do not observe evidence consistent with binding minimum age of employment regulation in a single country. The data are consistent with increases in household based activities when paid employment increases in general. Some countries have labor laws that allow light work before the minimum age of employment, and there is one country, Trinidad and Tobago, where the data are consistent with binding light work regulations.

Compulsory schooling regulation, which co-exists with minimum age regulation in many countries, presents both an econometric and interpretive problem in our results. When both regulations relax at the same time, we will not be able to attribute the changes in child time allocation to one particular regulation. On the other hand, if compulsory schooling law relaxes at a younger age than the minimum age of employment, then it creates a distortion in the age profile of child time allocation. This is problematic as we use age trends in child time allocation to estimate the counterfactual 
allocation at the minimum age of employment. We find evidence consistent with binding compulsory schooling regulations in one country, Burundi, where the law may interfere with our ability to infer whether minimum age regulations bind.

There are 17 countries in our data where the minimum age of employment is the same as the age at which schooling is no longer compulsory. In four of these countries we observe increases in paid employment at the minimum age but also observe increases in household based employment (inconsistent with binding minimum age of employment regulation). It is possible that these findings are driven by a combination of minimum age of employment regulation and compulsory schooling laws (although the change in schooling is not significant in any of the four). In fact, we find that the changes in paid employment are 9 times larger in magnitude in the pooled data in the selected group of countries where minimum age of employment and compulsory schooling regulations coincide compared to countries where schooling is not compulsory at the minimum age of employment. Hence, while overall, we find little to suggest a role for minimum age of employment regulation, as enforced, in combating child labor, there may be some benefit to coordinating employment and schooling regulation. That said, given the importance of household-level, child-invariant characteristics in child labor, it is not obvious that age-based regulation, as currently implemented and enforced, merits its current place at the center of anti-child labor policy.

In the next section of the paper, we present an overview of minimum age of employment regulation in our data. Section II considers how binding minimum age of employment regulation influences time allocation. Section III describes our empirical approach to measure the impact of minimum age regulation and the data we use. Section IV presents our findings. Section V concludes.

\section{Background on minimum Age of employment regulation}

Minimum age of employment regulations have existed in many high income countries since the late nineteenth century, and a series of international, industry specific minimum age of employment conventions were passed in the 1920s and 30s. The minimum age regulations studied herein have been influenced by two more recent international conventions.

ILO Convention 138 on the Minimum Age for Admission to Employment was passed on June 26, 1973 and has been ratified by 161 countries at the time of writing. A majority of ratifying countries had done so subsequent to 1996 . While there is considerable nuance in $\mathrm{C} 138$, three broad ideas inC138 are especially important in our discussion. ${ }^{2}$ First, C138 emphasizes that countries should raise the minimum age of admission to employment to no less than 15.Countries that are "insufficiently developed" may specify a transitional minimum age of employment of 14 . Second, it distinguishes between employment and light work, defining neither. Light work is codified on a national basis, but in principal it is work that does not conflict with school attendance and is not harmful to child health. Light work may be permissible from age 13. Third, it explicitly excludes "family and small-scale holdings producing for local consumption and not regularly employing hired workers" (article 5 section 3) from the provisions of the convention.

ILO Convention 182 on the Prohibition and Immediate Action for the Elimination of the Worst Forms of Child Labor was passed on June 17, 1999 and has been ratified by 
174 countries at the time of writing. ${ }^{3} \mathrm{C} 182$ defines a child as a person under 18 and proposes restrictions on certain categories of employment until age 18.It differentiates between unconditional worst forms of child labor from which children should be prohibited regardless of circumstance (includes all forms of modern slavery, prostitution and pornography, illicit activities and drug trade, and armed conflict) and hazardous child labor that national laws must define.

This paper examines the impact of minimum age of employment laws in all 59 countries with publicly available time allocation data from the second and third rounds of UNICEF's Multiple Indicator Cluster Surveys (MICS). ${ }^{4}$ Data collection instructions and survey questions are nearly uniform across each MICS country allowing for crosscountry comparisons. Round 2 of MICS occurred in 2000/01. Round 3 occurred 05/06. In the public use data, there are 28 African countries, 14 from Europe and Central Asia, 7 from East Asia and the Pacific, 6 from Latin American and the Caribbean, 3 from Middle East and North Africa, and 1 from South Asia. Nineteen countries have data in both MICS 2 and 3.The remaining 40 countries only have surveys in 1 of the 2 rounds.

In reviewing the minimum age of employment regulation in these MICS2 and MICS3 countries, their legislation generally looked like a combination of these principles from the two conventions. Appendix One of Edmonds and Shrestha (2012) contains a detailed description of laws in each country considered herein. Most countries have some form of light work allowable at some age under 14, a general easing of restrictions on most forms of employment around 14 of 15, and continued regulation on certain types of work until age 18. We define the minimum age of employment as the youngest age at which it is legal to pay a child to work full time outside the home (during the day, limited hours). We define the light work age as the youngest age at which a child may work for limited hours during the day in traditional (a common word) or family based activities.

Table 1 summarizes the regulation for light work and non-hazardous work for the countries considered in this study. When countries appear in both MICS2 and MICS3, they are listed once if minimum age regulations did not change substantively between rounds, and they are listed twice if their regulations changed. We report the minimum age of employment regulations in place at the time of the survey. Of the countries surveyed in both MICS2 and MICS3, only Gambia and Trinidad and Tobago have changed the basic minimum age of employment for non-hazardous work.

Fourteen is the modal minimum age of employment. Only Somalia does not appear to have any non-hazardous work regulation in place at the time of MICS3.Nineteen countries distinguish between light work and non-hazardous work, so the two ages are the same for a majority of the countries. Many countries contain exceptions from regulations for apprentices and work done in school, and we have coded the minimum ages in the table excluding apprenticeship regulation and allowances of work done in school.

An important issue that will arise in assessing the impact of the minimum age of employment regulation is whether the laws co-move with compulsory schooling regulation or natural school transition points.C138 stipulates that compulsory schooling laws should define the lower bound on minimum age of employment regulation if such laws require schooling beyond age 14. The last column of Table 1 contains the age at which schooling is no longer compulsory (or NA if schooling is not compulsory). Compulsory schooling regulations are sometimes based on grade completion, in which case we have translated that grade to an age using the rates of school completion reported by 
Table 1 Minimum age of employment \& compulsory schooling laws by country

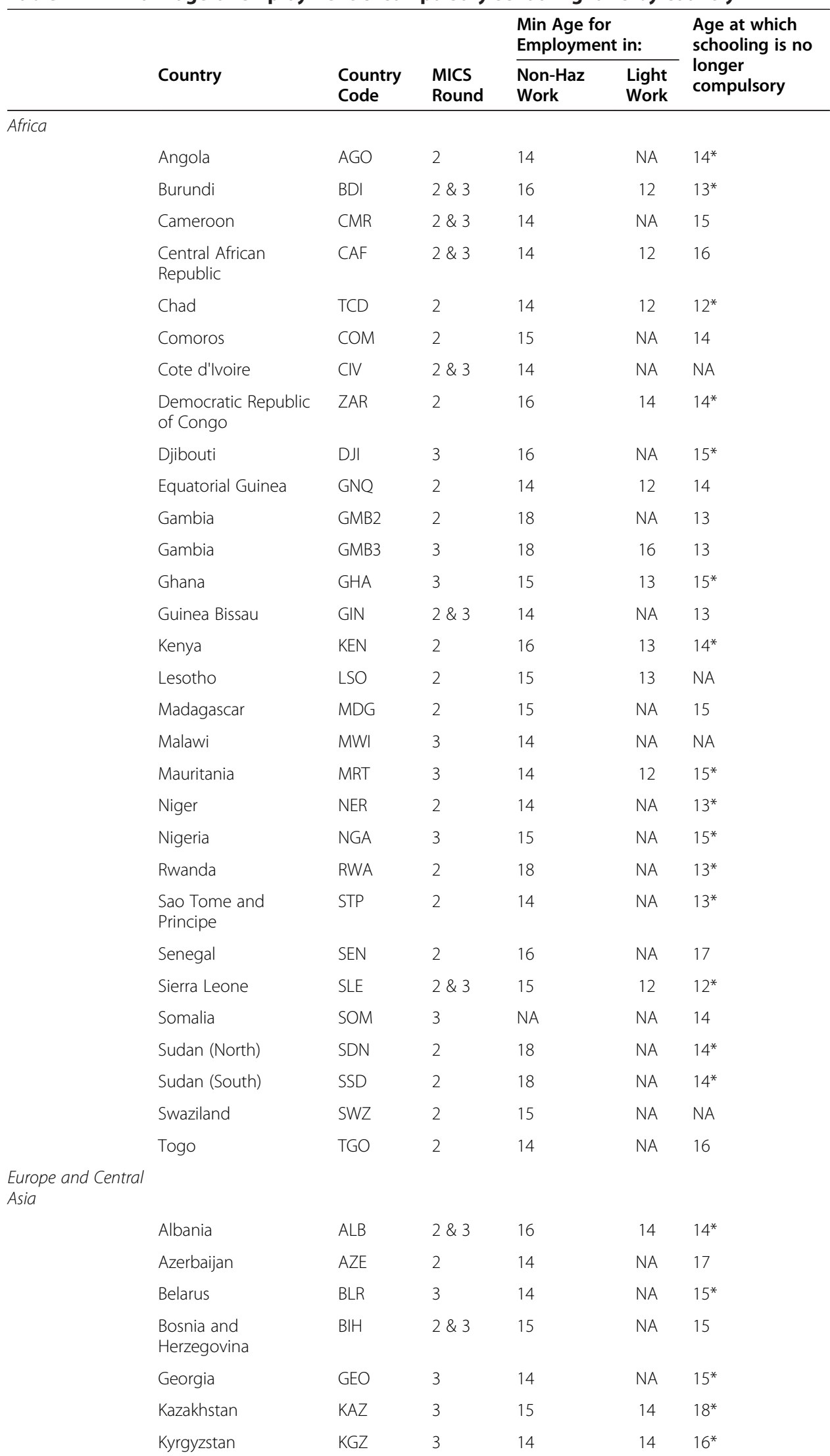


Table 1 Minimum age of employment \& compulsory schooling laws by country (Continued)

$\begin{array}{llllll}\text { Macedonia } & \text { MKD } & 3 & 15 & \text { NA } & 15^{*} \\ \text { Moldova } & \text { MDA } & 2 & 16 & 14 & 16^{*} \\ \text { Montenegro } & \text { MNE } & 3 & 15 & \text { NA } & 15^{*} \\ \text { Serbia } & \text { SER } & 3 & 15 & \text { NA } & 15^{*} \\ \text { Tajikistan } & \text { SJK } & 2 \& 3 & 16 & 7 & 16 \\ \text { Ukraine } & \text { UKR } & 3 & 15 & 14 & 18^{*} \\ \text { Uzbekistan } & \text { UZB2 } & 2 & 16 & 14 & 18^{*} \\ \text { Uzbekistan } & \text { UZB3 } & 3 & 16 & 14 & 19^{*}\end{array}$

East Asia and the

Pacific

$\begin{array}{llllll}\text { Laos } & \text { LAO } & 2 \& 3 & 15 & \text { NA } & 11^{*} \\ \text { Mongolia } & \text { MNG2 } & 2 & 14 & \text { NA } & 16^{*} \\ \text { Mongolia } & \text { MNG3 } & 3 & 14 & \text { NA } & 17^{*} \\ \text { Philippines } & \text { PHL } & 2 & 15 & \text { NA } & 12^{*} \\ \text { Thailand } & \text { THA } & 3 & 15 & \text { NA } & 15^{*} \\ \text { Vietnam } & \text { VNM } & 2 \& 3 & 15 & \text { NA } & 15\end{array}$

Middle East and

North Africa

$\begin{array}{llllll}\text { Iraq } & \text { IRQ } & 2 \& 3 & 15 & \text { NA } & 12^{*} \\ \text { Syria } & \text { SYR } & 3 & 15 & \text { NA } & 15^{*} \\ \text { Yemen } & \text { YEM } & 3 & 15 & \text { NA } & 15\end{array}$

South Asia

Bangladesh

$B G D$

3

12

NA 11

Latin America

\& the Carribean

$\begin{array}{llllll}\text { Bolivia } & \text { BOL } & 2 & 14 & \text { NA } & 14^{*} \\ \text { Dominican Republic } & \text { DOM } & 2 & 14 & \text { NA } & 14^{*} \\ \text { Guyana } & \text { GUY } & 2 \& 3 & 15 & \text { NA } & 15 \\ \text { Jamaica } & \text { JAM } & 2 \& 3 & 12 & \text { NA } & 12 \\ \text { Suriname } & \text { SUR } & 2 \& 3 & 14 & 12 & 12 \\ \text { Trinidad and Tobago } & \text { TTO2 } & 2 & 14 & 12 & 12 \\ \text { Trinidad and Tobago } & \text { TTO3 } & 3 & 16 & 14 & 12 \\ \text { Venezuela } & \text { VEN } & 2 & 14 & \text { NA } & 17\end{array}$

$\mathrm{NA}=$ No applicable law. The non-hazardous column is the minimum age of employment in the country, defined as the youngest age at which it is legal to pay a child to work full time outside the home (during the day, limited hours). The light work age is the youngest age at which a child may work for limited hours, during the day in traditional or family activities. Age at which child has completed compulsory schooling is the age at which the child is no longer required to go to school. When compulsory schooling is stipulated by grade, we impute the age based on the scheduled progression through grades. * =restriction is based on grade completion (ages are imputed based on scheduled school progression). See Appendix 1 for country level detail. In general, information on minimum age of employment comes from USDOL Trade and Development Act reports. Age at the end of compulsory schooling information is from the Right to Education project. Note: All ages are when restrictions are no longer in place. Thus, if schooling is compulsory through age 12, age 13 is when the child has completed compulsory schooling. That is, if schooling is compulsory through age 12 , the column will read age 13 , the age at which schooling is no longer compulsory.

UNESCO (see the appendix). These imputed compulsory schooling ages are marked with an asterisk. Four countries do not have any compulsory schooling regulation. Sixteen of the 59 countries have aligned their compulsory schooling laws with their minimum age of employment laws. The next section considers how these minimum age of employment regulations and compulsory schooling laws impact time allocation. 


\section{Theory - the impact of binding constraints on employment outside the home}

C138 explicitly excludes work inside the family from minimum age of employment regulation. Many countries have regulations that cover work inside the home, but even when it is law, few countries (high or low income) discuss enforcement of labor regulation inside the family. Hence, we treat enforced minimum age of employment regulation as affecting the availability of employment outside of the household. We begin with an unconstrained (separable) farm household model as a benchmark. We add binding constraints on employment outside of the home in section B.A challenge in our empirical work below is disentangling the effects of minimum age of employment regulation from compulsory schooling laws. We consider how the two child time allocation related laws differ in their effects in section $\mathrm{C}$.

\section{A. Unconstrained model}

We begin with a standard separable farm household model (e.g. Benjamin 1992) and add children and child labor. ${ }^{5}$ We adopt two modeling simplifications standard in the child labor literature (e.g. Basu and Van 1998). A family consists of one child and one adult. Adults and children are perfect substitutes in production subject to a productivity shifter. A child is equivalent to $a$ adults, where $a<1$. This is known as the substitution axiom. We begin with the unrestricted case of perfectly competitive labor markets where adults and children can freely sell their labor in the open labor market. Adult labor receives a wage $w$. Children then receive the wage $a w$.

Preferences are defined over the family's standard of living $s$, the child's education $e$, and the adult's and the child's leisure consumption, $\left\{l^{A}, l^{C}\right\}$ respectively, with the utility representation:

$$
U\left(s, e, l^{A}, l^{C}\right)
$$

Returns to education are understood to be part of the agent's utility from education. Education costs $p$ per unit. Total expenditures on education and the standard of living (price=1) come from net income from the family business and labor income:

$$
s+p e=F\left(L_{H}^{O}+L_{H}^{A}+a L_{H}^{C}\right)-w L_{H}^{O}+w L_{M}^{A}+a w L_{M}^{C}
$$

where $\left\{L_{H}^{O}, L_{H}^{A}, L_{H}^{C}\right\}$ respectively are the use of outside adult equivalent, adult, and child labor in the family business. F(-) is the household's production function (expressed in the same units as $s$ ) and exhibits a positive, diminishing marginal product. For economy, we have suppressed other inputs in the production function. Adult and child employment in the labor market are defined as $\left\{L_{M}^{A}, L_{M}^{C}\right\}$. Without constraints on the allocation of child time, the child and adult time endowments are:

$$
L_{M}^{C}+L_{H}^{C}+l^{C}=E^{C}-e
$$

and

$$
L_{M}^{A}+L_{H}^{A}+l^{A}=E^{A}
$$

Substituting (3) and (4) into (2), we have the full income constraint of the unrestricted model:

$$
s+w l^{A}+a w l^{C}+(p+a w) e=\Pi(w)+w E^{A}+a w E^{C}
$$

with 


$$
\Pi(w)=F\left(L_{H}^{O}+L_{H}^{A}+a L_{H}^{C}\right)-w L_{H}^{O}-w L_{H}^{A}-a w L_{H}^{C}
$$

The family allocates child time between types of employment so that the value of the child's marginal product in the home enterprise is equal to its price in the local labor market. Child leisure consumption and thus schooling is chosen so that the marginal rate of substitution between leisure and standard of living depends on the child's wage (aw):

$$
\frac{\partial u / \partial l^{C}}{\partial u / \partial s}=a w
$$

and the allocation of child time between leisure and schooling depends on the relative cost of schooling, which is:

$$
\frac{{ }^{\partial} u / \partial l^{C}}{\partial u / \partial} e \frac{a w}{p+a w}
$$

Household demand functions for education and leisure then depend on child wages, the price of schooling and endowment incomes:

$$
k=D^{k}\left(p+a w, a w, \Pi^{*}(w)+w E^{A}+a w E^{C}\right), k \in\left\{e, l^{c}\right\}
$$

where $\Pi^{*}(w)=\max _{L_{H}^{O}, L_{H}^{A}, L_{H}^{C}} F\left(L_{H}^{O}+L_{H}^{A}+a L_{H}^{C}\right)-w L_{H}^{O}-w L_{H}^{A}-a w L_{H}^{C}$

\section{B. Binding minimum Age of employment}

We assume minimum age of employment laws regulate child employment outside of the household. Consider a country with binding minimum age of employment laws that reduce child employment outside the household. Binding minimum age regulation does not affect the total amount the child works or the child's leisure consumption and schooling under the assumption of non-saturation. That is, so long as families have productive opportunities for labor inside the household, binding minimum age regulations change the location of work but not the amount of work.

To see that binding minimum age regulation induces substitution between activities, suppose that the binding constraint on work outside of the household adds the restriction of $L_{M}^{C}=0$ to (3). This has no effect on the opportunity cost of child leisure in the household so long as there is some adult (hired in or own) labor in the family enterprise. ${ }^{6}$ The key reason why minimum age restrictions do not impact schooling or work probabilities (only type of work) is that households are free to buy and sell other forms of labor. Faced with additional child labor in the family business, the household reduces its use of hired in and adult labor until the value of adult equivalent labor's marginal product equals the market wage. The value of adult equivalent labor in the family business will still be equal to the market wage. Hence, the value of the child's marginal product of labor is still aw. This produces the same marginal rate of substitution between leisure and standard of living as in equation (7).

It is possible that constraining all child labor to the family business reduces productivity in the family business to below the market wage and no adults would participate. We call this the "saturation" case. It is unclear how schooling and leisure consumption should change when binding constraints on paid employment induce saturation. Child 
productivity in the family enterprise is below what it was in the unconstrained case $\left(a F^{\prime}<a w\right)$.Household income declines. The opportunity cost of time in leisure is the agent's value of the child's productivity in the farm $\left({ }^{\partial} u / \partial s\right) a F^{\prime}$, and whether it is above or below the opportunity cost of time in leisure in the unconstrained case depends on the curvature in preferences for $s$. However, we should see a rise in household-based economic activity and specialization of adult employment towards work outside the home with saturation.

We are skeptical about the relevance of saturation for our analysis. What keeps the household from starting multiple businesses if the marginal product of labor in one is below market? Banerjee and Duflo (2007) document the prevalence of multiple enterprises within non-farm households, and the diversity of activities within farm households is broadly understood. We interpret this lack of specialization as being consistent with our hypothesis that even poor households can create multiple enterprises rather than face saturation in within-household labor supply.

\section{Binding compulsory schooling laws}

Binding compulsory schooling laws may be de facto or de jure. De facto compulsory schooling laws occur when strong norms exist within a society requiring students to attend school through a certain level (completing primary for example). De jure compulsory schooling laws entail legislation that require students to complete a certain level of school or continue in school through a certain age.

Binding compulsory schooling laws work differently than minimum age of employment laws. Minimum age of employment regulation restricts one type of job, inducing substitution to other types of work. Binding compulsory schooling laws put a lower bound on time in education and hence induce a decline in time to be allocated among other activities.

To model this binding constraint, we fix $e$ at some level $k$. The assumption that $\mathrm{k}$ is binding implies that education increases. Absent binding constraints on employment outside the home, this binding compulsory schooling law reduces endowment income by $(p+a w)^{*} k$. The coerced additional expenditure on schooling is $(p+a w)^{*}\left(k-e^{*}\right)$ where $\mathrm{e}^{*}$ is the solution to the unconstrained problem from section $\mathrm{A}$. The reduction in endowment income should reduce leisure and induce a substitution towards more work. It is possible that the decline in endowment time is sufficiently large such that there is less time available to work: $L_{M}^{C^{*}}+L_{H}^{C^{*}}>E^{C}-k$ where $L_{t}^{C^{*}}$ is the optimal time devoted to labor type $t \in\{M, H\}$ in the unconstrained problem of Section A. In this case, work also declines with compulsory schooling. Because of the substitutability of different types of labor (child, adult, outside), there is no clear prediction about the incidence of this decline in work across different locations.

In sum, binding constraints on the minimum age of employment decrease paid employment outside the home. They have no effect on schooling or labor force participation rates except under saturation. Binding compulsory schooling laws increase education yet have an ambiguous effect on work. They reduce income that can be consumed as living standards by forcing school expenditures and decreasing the time available for work. The reduced income increases demand for children to work, but they may bind such that the desired amount of work absent the constraint is not feasible under the compulsory schooling law. 


\section{Empirical approach}

\section{A. Design}

We assume that absent regulation, age trends in time allocation tend to be smooth. ${ }^{7}$ Minimum age regulations relax at certain ages. Hence, a natural empirical design is to test for breaks in age trends in time allocation at the ages where such regulations are relaxed. Perfectly enforced laws imply no paid employment outside of the home until laws are relaxed and some age trend in participation after employment is permitted. Perfect enforcement does not exist, and we focus our test on the weaker case of whether measurable changes in time allocation appear when minimum age of employment regulation is relaxed.

Our empirical approach is to fit a polynomial to model the age trends when restrictions are in place. We use that polynomial to predict the level of various time allocation measures if the age trend had continued. We then compare this predicted level of the dependent variable under the constrained age trend to the actual level observed in the first year that the restriction is eased. This approach is different than a more standard two-sided design, because we do not observe time allocation above age 14 for most countries in the MICS data. Appendix 2 of Edmonds and Shrestha (2012) compares our one-sided results to a more standard two-sided design for the sub-set of countries where the age range of the data make it feasible to use a two-sided estimator.

Specifically, let $y_{i c}$ represent the outcome of interest for child $i$ in country $c$. Define the cut age as the age where a minimum age of employment law relaxes. Below the cut age, the parametric assumption on the relationship between $y_{i c}$ and age $A_{i}$ under the constraint is simply:

$$
y_{i c}=\beta_{0}^{c}+\pi_{c}\left(A_{i}\right)+\varepsilon_{i c}
$$

where $\pi_{c}\left(A_{i}\right)$ is a polynomial in age. Age is transformed as a deviation from the cut age so that the interpretation of the constant is the estimate of the value of outcome $y$ at the cut age absent the easing of the restriction on minimum age of employment (10) is only estimated on the sample below the cut age, and the estimate of $\beta_{0}^{c}$ is compared with the sample estimate of $y$ at the cut age, $\bar{y}_{a=c u t}$. That is, the change in outcome $y$ associated with the easing of restrictions on employment is:

$$
\bar{y}_{a=c u t}^{c}-\beta_{0}^{c} \equiv D_{c u t}^{c}
$$

Estimates of $D_{\text {cut }}^{c}$ and its standard error can be obtained collapsing the data to country-age cells and regressing outcome $y$ on a polynomial in age (transformed so that age 0 is the cut age) and an indicator for the cut age using weighted least squares where the weight is the country population in that age cell. $D_{\text {cut }}^{c}$ is the coefficient on the cut age indicator. A similar empirical approach (albeit two-sided) is used by Oreopoulos (2006).

There is, of course, the issue of what order polynomial to fit to the pre-cut age trends in (10).Parametric RD approaches such as the one employed here are sensitive to the choice of specification. We opt for a data driven approach for the choice of the functional form of the polynomial using the Akaike Information Criterion (AIC) employed in Black et al. (2007) and discussed in Lee and Lemiuex (2011). Specifically for each country $c$ and each outcome variable $y$ separately we pick the order of the polynomial to minimize: $A I C_{y}^{c}=N^{c} \ln \left(\sigma_{y}^{2 c}\right)+2(p+1)$. Here, $\sigma_{y}^{2 c}$ is the mean squared error of the regression of outcome $y$ on a polynomial of order $p$ for country $c$ estimated on the 
country-level age-cell data from below the cut age. $N^{\mathrm{c}}$ is the number of observations in the weighted dataset. Given that we only observe ages in years, and we work on the age-cell level, our approach is intrinsically parametric.

One substantive issue in this approach is that we are estimating the impact of extending regulation by one additional year under the assumption that there is a smooth trend in the age pattern of time allocation before regulation is relaxed. Transition points in schooling naturally complicate this assumption. As a robustness check, we have estimated the impact of relaxing minimum age of employment regulations using only data from after the age primary school is usually completed. This restriction to the data limits the number of countries we can consider, but in those countries, we found in our basic results that age explains little variation in time allocation and that there is no statistically significant evidence consistent with binding minimum age of employment (although estimates are extremely imprecise when the data is restricted).The smooth age trends assumption is also complicated by other regulations. For example, if compulsory schooling relaxes before the minimum age and compulsory schooling regulation is binding, then the assumption of smooth age trends in estimating the impact of easing minimum age regulation would be incorrect. Likewise, if minimum age regulations bind and relax before compulsory schooling regulations are relaxed, then the assumption of smooth age trends in estimating the impact of easing compulsory schooling would be incorrect. We discuss the salience of these potential econometric problems caused by off-setting regulations in specific country contexts below.

\section{B. MICS data}

One important advantage of the MICS data for this type of work is that the time allocation module is nearly uniform across countries and between rounds. Thus, while the laws that we are evaluating differ from country to country, the basic measures of time allocation do not. Of course, even though the original questionnaires were largely identical, local understanding of the questions can differ.

The standard MICS questionnaire used in almost all countries contains 7questions in the child labor module. The reference period is defined as "the last week" for all questions. Questions are directed towards the mother or caretaker of all children age 5 through 14 although several countries extend the age range to 17 . We choose not to use the data for children 5-7 in our analysis. Participation in paid employment is rare in children below 8, and heterogeneity in school starting ages creates conceptual difficulties with the younger children. Pooled together, the data represent 158 million children 8-14.

The questionnaire measures two types of non-household employment. We define paid employment as a positive answer to the question of whether the child did any kind of work for pay for someone who is not a member of the surveyed household. While "work" is not defined, the questionnaire stipulates that pay may be for cash or in kind. Unpaid, nonhousehold employment is defined as working in any kind of work over the past week for someone who is not a member of the household without pay. The questionnaire does not allow the respondent to work in both paid and unpaid non-household employment. It asks for total hours in the last week in the two types of non-household employment, and it explicitly instructs respondents to combine hours across all non-household jobs.

The questionnaire collects information about household based activities as well. It includes questions about participation and hours in unpaid household services in the 
last week. It lists "household chores such as shopping, collecting firewood, cleaning, fetching water, or caring for children" as examples of these unpaid household services. The questionnaire also asks about participation and hours in the last week in "other family work," giving work in "the farm or in a business or selling goods in the street" as examples. We label this category "household based economic activity."

Several aggregates will be considered in this discussion. Unpaid economic activity includes household based economic activity and unpaid, non-household employment. Economic activity combines unpaid economic activity with paid employment. Work combines economic activity with unpaid household services. Household based economic activity and services combines' household based economic activity with unpaid household services.

Schooling data is also collected in a consistent manner across countries in each round, but the questionnaire changes slightly but substantively between round 2 and round 3. Both rounds asked whether the child attends school during a reference year and both collect information on number of days attended in the last week. Unlike the time allocation questions where the last week is poorly defined, the school attendance question asks explicitly references "last (day of the week)." This should be how the enumerators implement "last week" in the child labor module as well, but the questionnaire for schooling is more explicit in this regard. There are two other important differences between rounds. First, the age range for school attendance data changes. Schooling attendance is collected for all children age 5-17 in MICS2 and 5-24 in MICS3.Second, MICS 3 is more specific about the reference school year for the attendance question. Round 2 asks about the current school year. Round 3 explicitly identifies the reference year. This could be substantive during interim periods when it is unclear whether the current year would reference the year about to start or the year recently completed (enumerators should have made this clear). Idle children are children that neither work (in economic activity or unpaid household services) nor attend school. We suspect measurement error is an important component of idle status.

Table 2 contains time allocation summary statistics for the data used in this study. Column 1 pools all the data available in the MICS data. Column 2 contains summary

Table 2 Participation in the last 7 days in various activities

\begin{tabular}{|c|c|c|c|c|c|}
\hline \multicolumn{6}{|l|}{ Restricted to Ages 8-14 } \\
\hline & \multirow[b]{2}{*}{ Full Sample } & \multicolumn{2}{|c|}{ Survey Round } & \multicolumn{2}{|l|}{ Region } \\
\hline & & MICS2 & MICS3 & Sub-Saharan Africa & Rest of World \\
\hline Population in Millions & 156 & 72 & 84 & 72 & 85 \\
\hline Paid Employment & 2.95 & 3.08 & 2.85 & 3.60 & 2.42 \\
\hline Unpaid Economic Activity & 26.23 & 26.78 & 25.76 & 37.20 & 17.05 \\
\hline Economically Active & 27.98 & 28.61 & 27.45 & 38.82 & 18.91 \\
\hline Unpaid Household Services & 74.91 & 76.78 & 73.35 & 78.60 & 71.84 \\
\hline Household Based Activity & 78.38 & 80.23 & 76.84 & 82.06 & 75.31 \\
\hline Any Type of Work & 79.54 & 80.81 & 78.48 & 83.46 & 76.27 \\
\hline Attends School in Last Year & 81.49 & 80.83 & 82.05 & 71.66 & 89.69 \\
\hline No School nor Any Type of Work & 3.58 & 3.16 & 3.93 & 5.44 & 2.05 \\
\hline
\end{tabular}

Authors' calculations from publically available MICS $2 \& 3$ data. See Table 1 for list of countries. Data weighted to be nationally representative and to reflect size of country's population. 
statistics for the pooled MICS2 data. Column 3 contains summary statistics for the pooled MICS3 data. Column 4 bifurcates the pooled MICS rounds into Sub-Saharan Africa (SSA) and other geographic regions.

The data represent 156 million children, 72 million of whom are in SSA. Three percent of children work in paid employment. Twenty-six percent are engaged in unpaid economic activity. Twenty-eight percent are economically active. Seventy-five percent are engaged in unpaid household services. Seventy-eight percent are in household based activities (combining unpaid household services with household based unpaid economic activity). Eighty percent are engaged in some kind of work. Eighty-two percent attend school, and 4 percent are idle, neither working nor attending school. All work measures are lower and schooling is higher in MICS3 compared to MICS2. Working children are more prevalent in the SSA countries with unpaid economic activity standing out as a substantive difference. The prevalence of unpaid economic activity is more than double in SSA compared to non-SSA countries. Summary statistics for time allocation by country for children 8-14 are in Edmonds and Shrestha (2012). Figure 1 pools the data from each country (combining MICS data when applicable) and

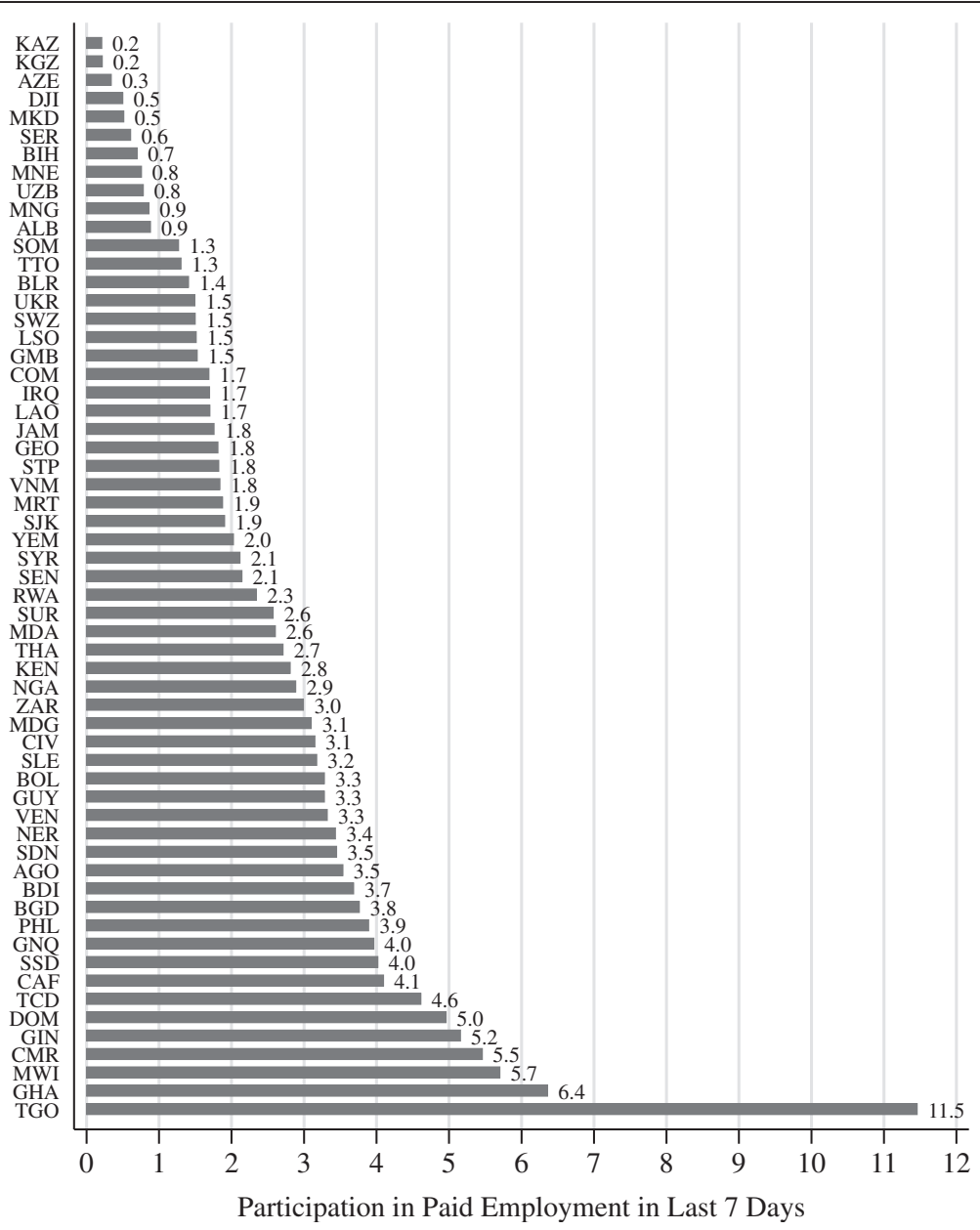

Figure 1 The prevalence of paid employment for children $8-14$ in the week before survey by country. 
plots participation rates by country. In our data, paid employment is most prevalent in Togo and least prevalent in Kazakhstan.

\section{Main findings}

\section{A. Analysis of variance}

Enforced minimum age and compulsory school laws change the age distribution of activities. We begin with the question: how important is age in time allocation? Time allocation varies with age for reasons other than regulation. Physical, mental, and emotional capacities for different types of work vary with human development. While there is ample scope for age to be an important determinant of time allocation even when minimum age regulations are completely unenforced, age appears to have a minor, often negligible, influence on time allocation. On average, age can account for 0.7 percent of the variation paid employment. The lack of explanatory power for age contrasts sharply with other influences that vary at the household, not child level. In African MICS countries, age accounts for 0.5 percent of the variation in participation in paid employment (1.1 percent in non-African MICS countries).In contrast, household-level characteristics can account for 67 percent of the variation in participation in paid employment in the African-MICS countries (58 percent in non-African).

To examine the importance of age-specific attributes, we begin by examining how much of the variation in participation in paid employment can be attributed to age. Figure 2 is a histogram of the fraction of the variation in paid employment that can be explained by age for each of the countries in our data. This is the R2 of a regression of paid employment on a vector of age dummies without controlling for household attributes run separately for each country. The average R2 in the data in Figure 2 is 0.7 percent.

The low explanatory power of age contrasts with the ability of household characteristics to account for variation in paid employment. To compare the explanatory power of

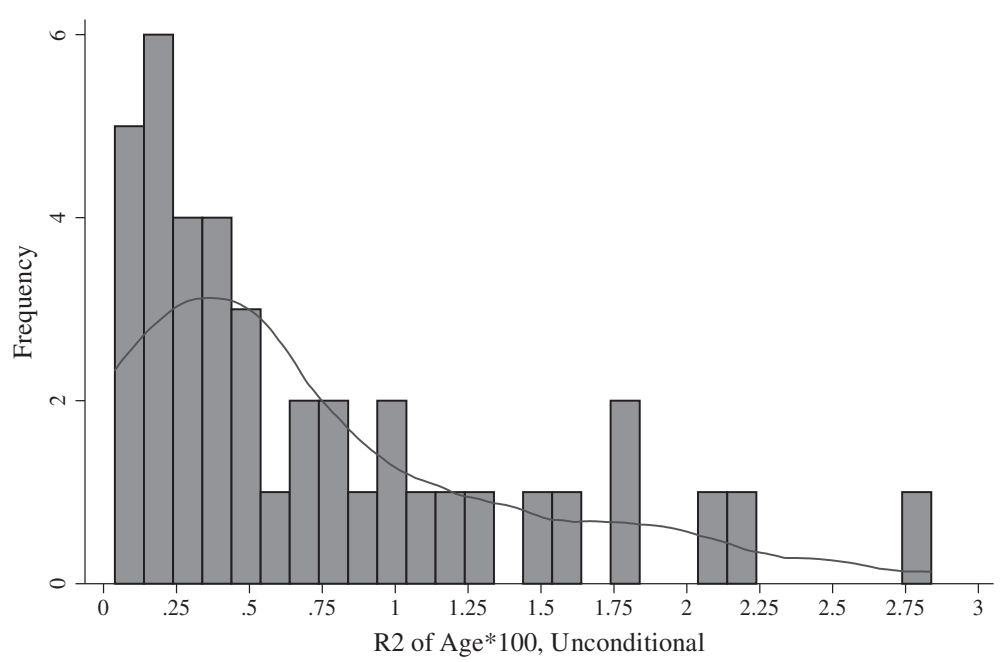

Figure 2 Fraction of variation in paid employment explained by age. Histogram of R2 from regression of paid employment in last 7 days on age separately by country for all MICS countries with paid employment data listed in Table 1. Limited to ages 8-14. Bin width is 0.1 (one tenth of one percent). Data range from 0.04 to 2.78 with a mean of 0.73 . An R2 of 1 in the picture means that 1 percent of the variation in paid employment can be explained by age. 
age with other child and household attributes, we regress outcomes (we choose paid employment, school attendance, and idle) on dummy variables for age, gender, and household. We then compute what fraction of the total variation in the outcome can be explained by each component of the model as well as the model as a whole. This decomposition exercise is obviously only identified for households with more than 1 child present of school age. We limit our sample accordingly.

Table 3 is this analysis of variance for the pooled data. All individuals are weighted by their inverse sampling probability. The analysis of variance in the pooled data is thus representative of 158 million children 8-14. Each cell contains the fraction of the total sum of squares that can be attributed to the row variable for all countries pooled (column 1), all African MICS countries (column 2), and all non-African MICS countries (column 3). The first four rows present our findings for paid employment, the next four contain school attendance, and the bottom four examine idle status. Age can explain 0.71 percent of the variation in paid employment in all countries combined, 0.48 percent in Africa, and 1.09 percent in other countries. Household characteristics account for 63.29 percent of the variation in paid employment in all countries, 67.77 percent in Africa.

Figure 3 presents the results of computing this analysis of variance for each country separately (Table 3A and B of Edmonds and Shrestha 2012 contains the detailed results). Figure $3 \mathrm{~A}$ is a histogram of the partial R2 of age from estimating the model of Table 3 in explaining paid employment. The partial R2s are close to the unconditional R2 in Figure 2 although they are often smaller in magnitude. Age differences are most substantive in Syria, Vietnam, and Bangladesh. Age can never explain more than 2.16 percent of the variation in participation in paid employment.

Table 3 Analysis of variance in key outcomes

\begin{tabular}{lllll}
\hline $\begin{array}{l}\text { Children 8-14, Pooled Results } \\
\text { Dependent Variable }\end{array}$ & Explanatory Variable & All Countries & Africa & Non-Africa \\
\hline Paid Employment & Age & & & \\
& Gender & 0.71 & 0.48 & 1.09 \\
& Household & 0.09 & 0.06 & 0.14 \\
& Model & 63.29 & 67.14 & 57.70 \\
& & 64.22 & 67.77 & 59.17 \\
Attends School & Age & & & \\
& Gender & 0.56 & 0.16 & 2.28 \\
& Household & 0.18 & 0.33 & 0.05 \\
& Model & 70.36 & 72.77 & 61.06 \\
Idle (No School nor Any Type of Work) & & 71.30 & 73.68 & 63.68 \\
& Age & & & \\
& Gender & 0.54 & 0.85 & 0.27 \\
& Household & 0.04 & 0.07 & 0.02 \\
& Model & 62.16 & 66.48 & 51.20 \\
\hline
\end{tabular}

For each dependent variable, we regress the dependent variable on dummies for age, gender, and household. Each cell is the fraction of the total sum of squares in the dependent variable that can be explained by the row variable in the model (the partial sum of squares divided by the total sum of squares). The model row contains the explained sum of squares as a fraction of the total sum of squares. Pooled results are estimated by combining all survey data and weighting by the inverse sampling probability for each individual. Africa restricts the sample to countries listed as such in Table 1. Non-Africa restricts the sample to the remaining countries. 

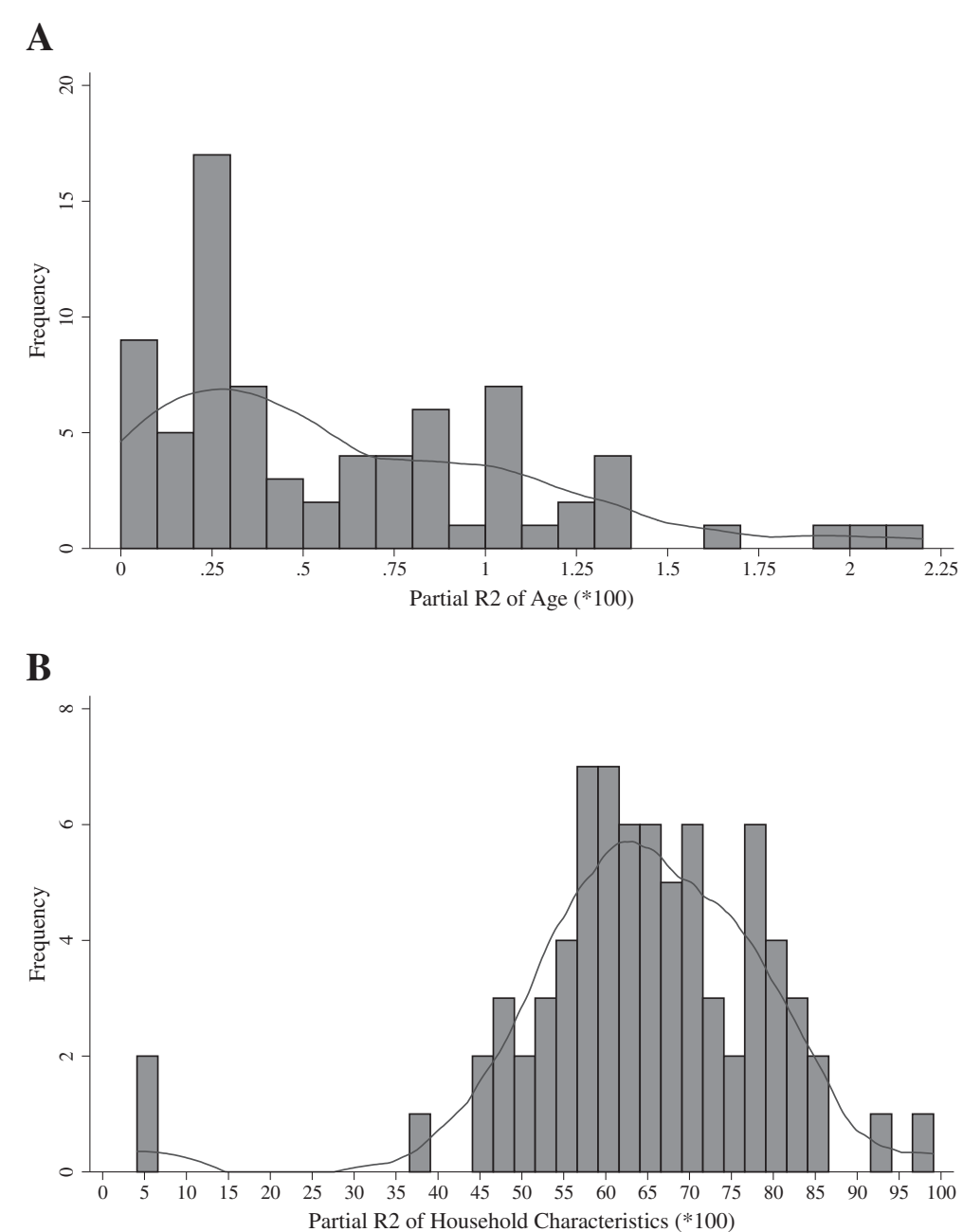

Figure 3 Fraction of variation in paid employment explained by age and household characteristics. A. Age, B. household attributes. Histograms of percent of variation in paid employment for children 8-14 explained by age (panel A) and household fixed effects (panel B) in a regression of paid employment on age effects, gender, and household fixed effects. Bin width is 0.1 (one tenth of one percent) in panel A and 2.5 in panel B. A partial R2 of 1 is 1 percent.

We focus on age, because binding minimum age of employment regulation impacts the distribution of activities across ages. It is useful to compare the explanatory power of age to gender and household attributes. In African countries, gender accounts for less than a tenth of a percent of the variation in paid employment. Lesotho stands out with gender accounting for 0.68 percent of the variation in paid employment. Overall, gender accounts for little of the variation paid employment.

The importance of household attributes for time allocation contrasts with age. Household attributes can account for 63 percent of the variation in the prevalence of paid employment, 70 percent of the variation in school enrollment, and 62 percent of the variation idle status. The individual country partial R2s are in Figure 3B. The figure is constructed identically to Figure 3A except the figure is a plot of the partial R2 for the household fixed effects in explaining variation in paid employment. The contrast between Figure 3A (partial R2 for age) and Figure 3B (partial R2 for household fixed 
effects) is striking. The importance of child-invariant household attributes may be driven by low family income, parental characteristics and attitudes, or community level attributes such as the prevalence of certain types of employment or schools. Outside of Comoros and Cote d'Ivoire where we believe the household identifiers are incorrect (the far left tail of Figure 3B), household attributes account for a majority of the variation in paid employment in 50 of the 57 countries. ${ }^{8}$

\section{B. The impact of light work restrictions}

The fact that the variation in paid employment with age is small does not have any implication for whether minimum age regulations influence time allocation. For example, suppose paid employment was flat with respect to age, but the relaxation of constraints lead to a small, one-time jump in the prevalence of paid employment. Age would still explain little of the total variation in paid employment even though there was an effect of regulation.

In this section, we report estimates of (11) for each activity category at the age at which light work is permitted (or light work regulation is no longer binding).The next section contains estimates for minimum age of employment regulation, and the final section focuses on compulsory schooling regulation. Obviously, our findings in each section are limited to countries that relax regulation within the age ranges covered in the data. This constraint means that different countries will be included in the results for each section of the paper. Unlike the previous section, where we only used data for children age 8-14, in this section, we use data between ages 8 and the cutoff for the regulation in estimating (11) when the older data is present and relevant.

Table 4 contains results aggregating all countries together and separating out the African countries. For paid employment, the "base" amount is the projected prevalence of paid employment if the time trend in paid employment under regulated ages was extended to the year where the regulation is not longer in place. The "change" is the difference between the actual incidence of paid employment at the age the law relaxes compared to the base level. Thus the "base" level of paid employment is the counterfactual of what paid employment would be at the age where regulation is relaxed absent the relaxation of the regulation on the minimum age of employment. Dividing the change by the base gives the percentage change in paid employment associated with the relaxation of the regulation. All other columns of the table report the "change" column for the dependent variable listed as the column header. We omit the base level for economy for all other outcomes.

We focus on the light work results in this section. When light work is allowed, minimum age regulations are still binding. However, light work regulation would prevent any child employment. Hence, the age at which light work is permitted is the youngest age for which we might see paid employment if the regulations were binding and enforced. We expect the easing of the prohibition on light work to have the same comparative statics as discussed for the relaxation of minimum age of employment regulation earlier in the paper. We should see an increase in paid employment and a decline in household based activity without changes in school attendance.

Our findings for the pooled data are in Table 4. There is no evidence of a change in participation in paid employment with the easing of light work regulation in the pooled data or in the African countries. While the changes in paid employment are especially small, we do not observe t-statistics greater in magnitude than 1 for any of the time allocation measures in Table 4 in Africa. In the combined data, the only t-statistic greater than 1 is 
Table 4 Changes in time allocation at the age of relaxation of regulation, pooled findings

\begin{tabular}{|c|c|c|c|c|c|c|c|c|c|c|}
\hline \multirow[b]{2}{*}{ Region } & \multirow[b]{2}{*}{ Regulation } & \multicolumn{2}{|c|}{ Paid employment } & \multirow{2}{*}{$\begin{array}{l}\text { Unpaid } \\
\text { economic } \\
\text { activity }\end{array}$} & \multirow{2}{*}{$\begin{array}{l}\text { Economic } \\
\text { activity }\end{array}$} & \multirow{2}{*}{$\begin{array}{l}\text { Unpaid Hh. } \\
\text { services }\end{array}$} & \multirow{2}{*}{$\begin{array}{l}\text { Hh. Based EA } \\
\text { \& services }\end{array}$} & \multirow{2}{*}{$\begin{array}{l}\text { Any } \\
\text { Work }\end{array}$} & \multirow{2}{*}{$\begin{array}{l}\text { Attend } \\
\text { school }\end{array}$} & \multirow[t]{2}{*}{ Idle } \\
\hline & & Base & Change & & & & & & & \\
\hline \multicolumn{11}{|c|}{ All Countries } \\
\hline & Light Work & 0.037 & -0.001 & 0.069 & 0.070 & -0.060 & -0.053 & -0.052 & -0.051 & 0.027 \\
\hline & & $(0.003)$ & $(0.006)$ & $(0.159)$ & $(0.160)$ & $(0.081)$ & $(0.090)$ & $(0.092)$ & $(0.039)$ & $(0.033)$ \\
\hline & Minimum Non-Hazardous & 0.061 & 0.007 & -0.013 & 0.001 & -0.016 & -0.019 & -0.012 & -0.001 & -0.007 \\
\hline & & $(0.003)$ & $(0.004)$ & $(0.040)$ & $(0.041)$ & $(0.032)$ & $(0.034)$ & $(0.032)$ & $(0.021)$ & $(0.011)$ \\
\hline & Compulsory Schooling & 0.056 & 0.003 & 0.017 & 0.024 & 0.010 & 0.010 & 0.015 & -0.105 & 0.027 \\
\hline & & $(0.003)$ & $(0.004)$ & $(0.028)$ & $(0.030)$ & $(0.076)$ & $(0.075)$ & $(0.072)$ & $(0.046)$ & $(0.023)$ \\
\hline \multicolumn{11}{|l|}{ Africa } \\
\hline & Light Work & 0.050 & 0.000 & 0.042 & 0.043 & -0.055 & -0.048 & -0.046 & -0.040 & 0.026 \\
\hline & & $(0.005)$ & $(0.009)$ & $(0.199)$ & $(0.202)$ & $(0.162)$ & $(0.177)$ & $(0.179)$ & $(0.100)$ & $(0.097)$ \\
\hline & Minimum Non-Hazardous & 0.065 & 0.007 & -0.087 & -0.086 & 0.065 & 0.069 & 0.070 & -0.020 & 0.014 \\
\hline & & $(0.005)$ & $(0.006)$ & $(0.074)$ & $(0.074)$ & $(0.051)$ & $(0.059)$ & $(0.062)$ & $(0.045)$ & $(0.026)$ \\
\hline & Compulsory Schooling & 0.049 & 0.010 & 0.008 & 0.012 & 0.016 & 0.022 & 0.010 & -0.006 & -0.008 \\
\hline & & $(0.008)$ & $(0.015)$ & $(0.099)$ & $(0.105)$ & $(0.107)$ & $(0.113)$ & $(0.115)$ & $(0.025)$ & $(0.051)$ \\
\hline
\end{tabular}

Change in column variable at age of relaxation of regulation listed in row. All countries in region pooled. Age cell level regressions. Each cell weighted by population. 


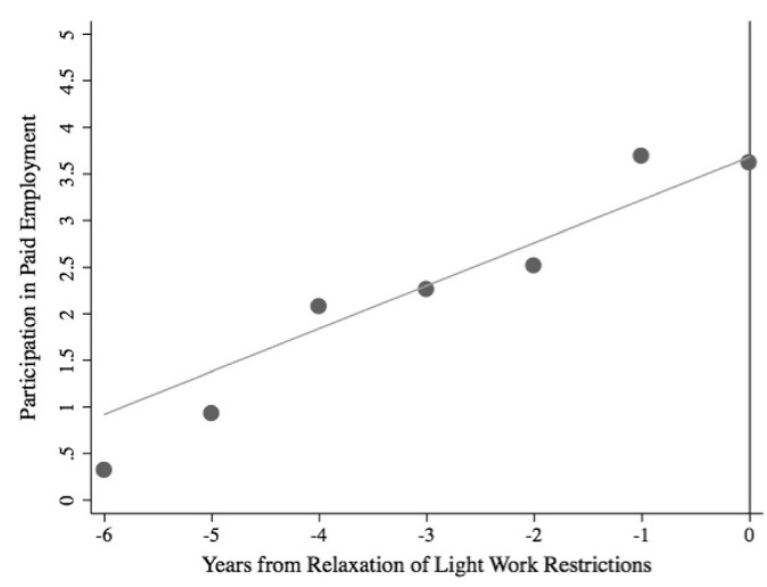

Figure 4 Change in paid employment with relaxation of light work restrictions.

in magnitude is for school attendance, but the estimated percentage change is still less than 10 percent and not significant.

The lack of an impact of easing light work regulation in the aggregate data is clear in Figure 4. For Figure 4, we have transformed every child's age to a measure that is years since the relaxation of light work regulation in the country (for countries with light work regulation only). Hence -1 implies 1 year before the youngest age that light work regulation is no longer binding, and 0 is the first age a child may work in light work. It is clear that the incidence of paid employment when light work is allowed does not deviate from the trend when restrictions are in place.

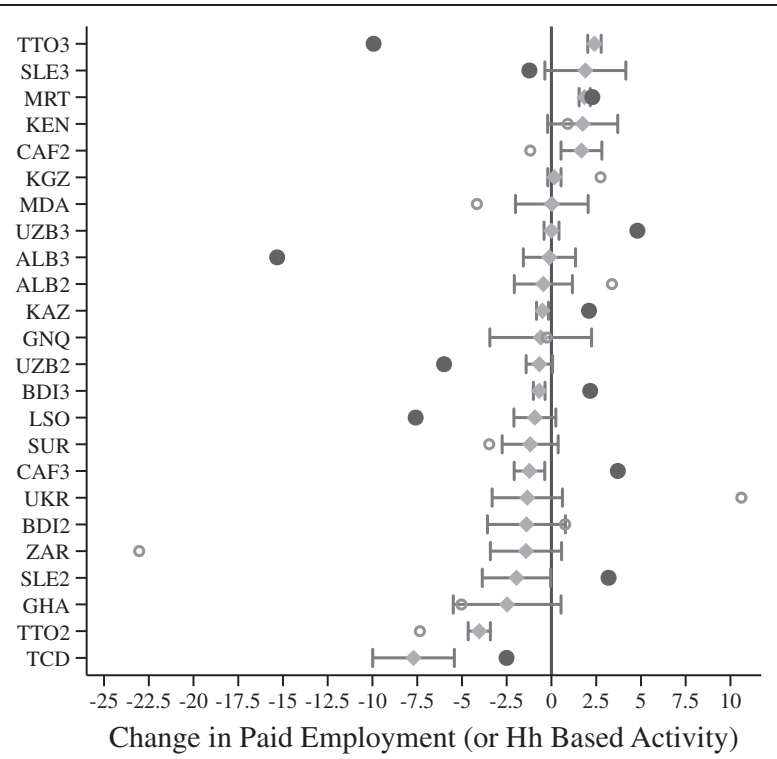

Figure 5 Change in paid employment and household based employment at minimum age for light work by country. Change in paid employment at age light work is allowed (diamonds with 95 percent confidence intervals pictures) and change in household based activity at age light work is allowed (circles / filled = reject null of no change with 95 percent confidence). A "2" after the country code indicates the data comes from the MICS2 survey for the country (" 3 " for MICS3). Country codes in Table 1. 
Figure 5 contains results by outcome and country. The figure contains the change in paid employment confidence intervals and point estimate (diamond). The figure also contains the estimated change in household based activity and marks that with a circle. A solid circle indicates that we reject the null of no change in household based activity with 95 percent confidence. A hollow circle indicates 0 is within the 95 percent confidence interval for the parameter. Each row of the figure contains the results from two different regressions, and each row is estimated separately. In general, countries are identified by their country code (see Table 1), but when multiple MICS are available for the country we have added a 2 or 3 to the country code to make it clear whether the results come from MICS2 or MICS3 for the country.

We observe increases in paid employment with the easing of light work restrictions in 8 countries. We can reject the null that these changes are 0 at a p-value of 0.10 in Mauritania and 0.05 in Trinidad and Tobago. In Mauritania, we observe an increase in household based activities at the age of easement of regulation that is similar in magnitude to the increase in paid employment we find. Hence, we do not find evidence consistent with binding light work regulation in Mauritania.

Interestingly and nicely illustrating the importance of examining whether we observe changes that match the prediction of theory, in one round of MICS for Trinidad and Tobago, we observe a decline in paid employment with the easing of regulation. We observe an increase in the other. Focusing on the 2006 data where we observe the increase in paid employment, we also observe a decline in household based activities and no change in schooling. Hence, the pattern observed in 2006 in Trinidad and Tobago is consistent with binding light work regulation. Between 2000 and 2006, Trinidad increased its regulation so the light work age in 2006 is the minimum age of employment in 2000.This evidence from Trinidad and Tobago, which may reflect the impact of the easing of light work regulation or lagged minimum age of employment regulation is the only evidence of enforced employment regulation in this study. It is worth noting that compulsory schooling was lifted before light work was allowed in Trinidad and Tobago, so this is one country where our econometric assumption of smooth age trends before light work is permitted maybe problematic. However, there is no evidence in Trinidad and Tobago of binding compulsory schooling regulation in the discussion below.

\section{The impact of minimum Age (Non-hazardous restrictions)}

Minimum age regulations are more prevalent and more restrictive than light work regulation. Hence, we expect a larger impact of their relaxation if they are binding. One rarely hears accounts of the enforcement of light work regulation, but attention is more often brought to minimum age of employment regulation. In our discussion, we do not discuss the impact of removing the restrictions on hazardous work and the worst forms of child labor that persist until older ages, because we do not have data on time allocation at older ages and generally those restrictions are on less prevalent work. The minimum age regulations are the relevant regulation for the most common types of paid employment in which children may work.

In the pooled data, there is little to suggest an impact of the relaxation of minimum age of employment restrictions. These estimates are in Table 4 above. Figure 6 presents the pooled findings for paid employment graphically. The construction of the figures is identical to Figure 4, so that 0 is the minimum age at which work is permitted outside 


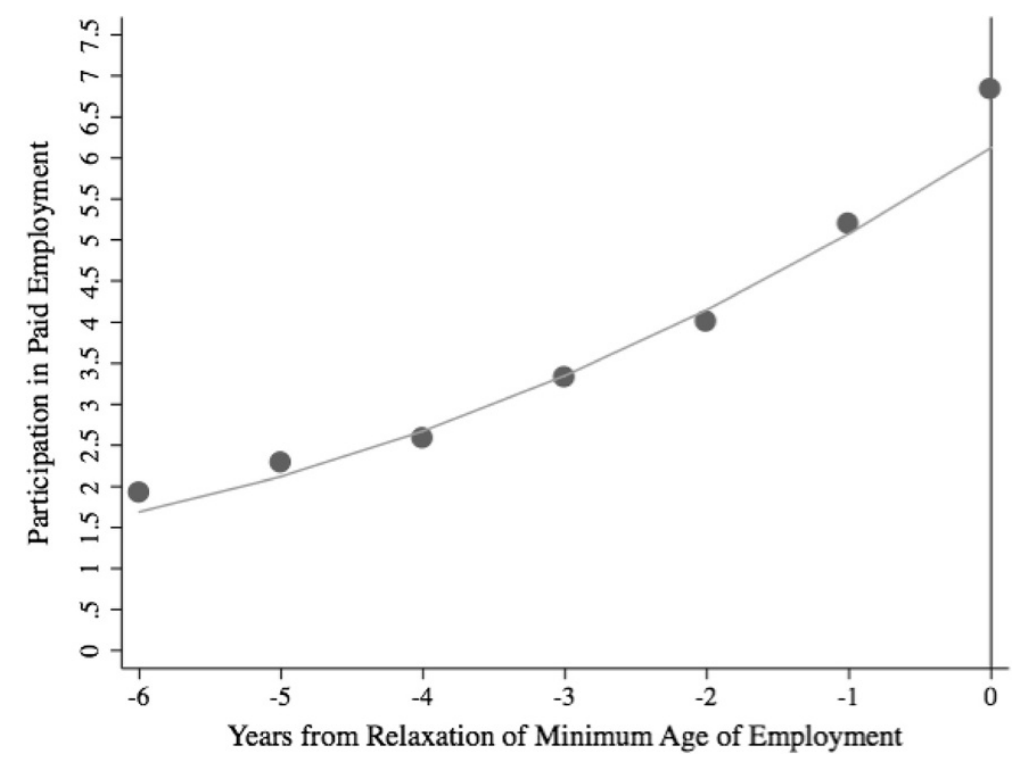

Figure 6 Change in paid employment with relaxation of minimum age for non-hazardous work restrictions.

of worst forms of child labor. Paid employment is higher than would be predicted by the trend from the ages when employment was restricted. The magnitudes are such that the easing of minimum age of employment regulation increases paid employment by slightly more than 10 percent, although this change is not statistically significant. In Africa (Table 4), we also observe an increase in work inside the household too. We observe a decrease outside of Africa, but both these changes in household based activity are not statistically significant or large in magnitude.

Figure 7 mimics the format of Figure 5 and presents the changes in paid employment and household based activity graphically. Confidence intervals and point estimates for changes in paid employment (diamonds) and household based activities (circles) are pictured. We observe statistically significant increases in paid employment with the relaxation of minimum age regulation in one African country, Nigeria. The magnitude of the estimated increase in paid employment is large in Nigeria, over 50 percent. Bolivia, Bangladesh, and Trinidad and Tobago are the three other countries in the world where we observe statistically significant increases in paid employment at the minimum age for employment.

With a large number of regressions, we expect to see statistical significance by happenstance. In fact, in Figure 7, we observe more statistically significant decreases in paid employment at minimum age of employment than increases. We cannot rely solely on tests of statistical significance in evaluating whether we are observing effects of easing labor regulation. Hence, we examine the countries where we observe significant increases in paid employment for evidence of shifts in work from inside to outside the household. In Nigeria, there is some decline in participation in household based activity, although the change is roughly a third of the magnitude of the increase in paid employment. We also observe large decreases in schooling in Nigeria at the minimum age of employment. In Table 1, it is noted that schooling is no longer compulsory at the minimum age of employment, and the patterns observed in the data (see Edmonds 


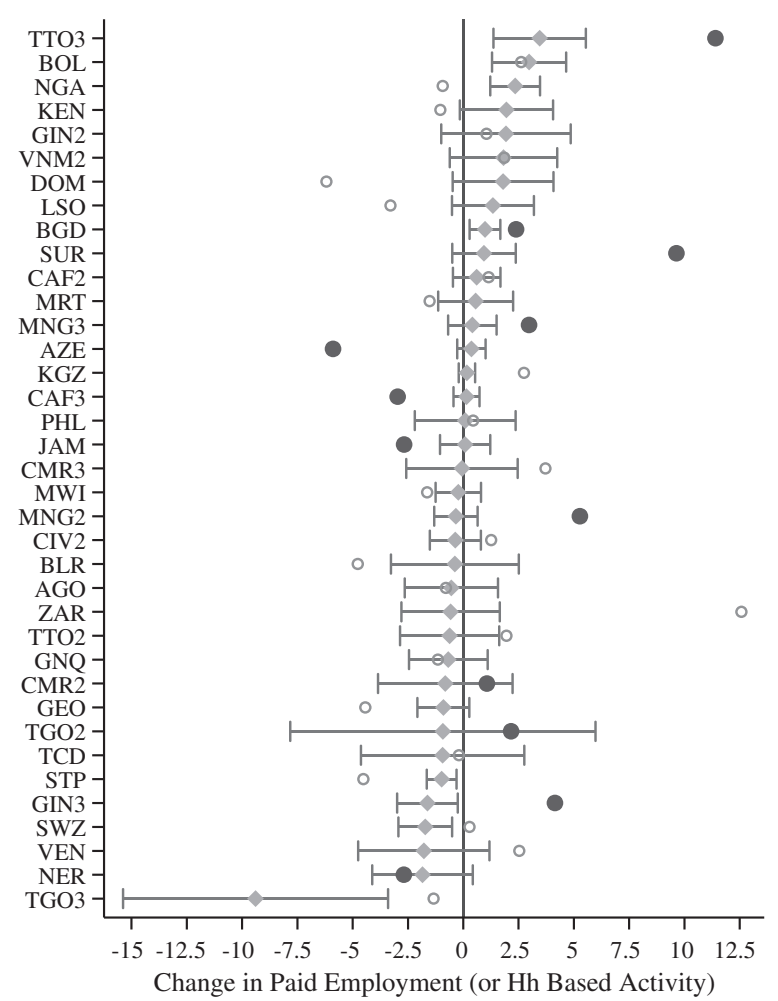

Figure $\mathbf{7}$ Change in paid employment and household based activity at minimum age of employment by country. Change in paid employment at minimum age of employment (diamonds with 95 percent confidence intervals) and change in household based activity at minimum age of employment (circles / filled = reject null of no change at 95 percent). A " 2 " after the country code (see Table 1) indicates the data comes from the MICS2 survey for the country (" 3 " for MICS3).

and Shrestha 2012) are consistent with the effects of the relaxation of compulsory schooling laws.

In Bangladesh, the observed pattern of responses even more clearly follows the compulsory schooling law predictions although compulsory schooling laws are believed to relax a year before minimum age regulation. Paid employment increases by 1 percentage point (25 percent) at the minimum age of employment; the prevalence of any work increases by 3 percentage points; and school attendance declines by 9 percentage points. We observe this pattern that appears consistent with relaxed schooling laws, although in the next section we find no change in schooling at the ages where compulsory schooling is dejure relaxed. This may be a case where de facto schooling norms and de jure schooling regulations differ.

In Bolivia, we observe changes in time allocation that suggest that the statistically significant finding of an increase in paid employment may be spurious. We observe a statistically insignificant increase in household based activity that is similar in magnitude to the increase in paid employment. Hence, we do not observe the pattern of changes in time allocation suggested by the theory.

For Trinidad and Tobago, we observe increases in paid employment and increases in household based activities that, together, are nearly double the statistically significant decrease in schooling we observe. If, in fact, light work regulations bound in Trinidad and Tobago, the assumption of smooth age trends under binding minimum age 
regulation would not be correct. Overall, these Trinidad and Tobago findings for minimum age regulation are difficult to interpret. Like Bangladesh, they are consistent with relaxing compulsory schooling laws. Like Bangladesh, we find no evidence of binding compulsory schooling laws below, so we could be capturing de facto schooling transition points. We have an additional problem here that our light work findings imply substantive concerns about our econometric approach to estimating the impact of relaxing minimum age regulation.

While these are the statistically significant findings, there are many changes in paid employment that are not statistically significant. We observe the general pattern suggested by binding minimum age regulation: increases in paid employment matched by declines in work in the household. To assess this, we plot the estimated changes in paid employment at the minimum age of employment against the estimated changes in household based activity in Figure 8. The figure includes the linear regression line (solid, bold) and the 45-degree line (light, dashed). While binding minimum age regulation implies that changes in paid employment and household based activity should be negatively correlated, we observe that the association is positive in the data. In fact the quadrant of increasing paid employment and decreasing household based activity has the fewest observations of any of the combinations.

\section{The impact of compulsory schooling laws}

For the present study, compulsory schooling regulation may present an econometric problem that prevents us from estimating a counterfactual prevalence of paid employment or a confounder that makes it difficult to use theory to identify type I errors.

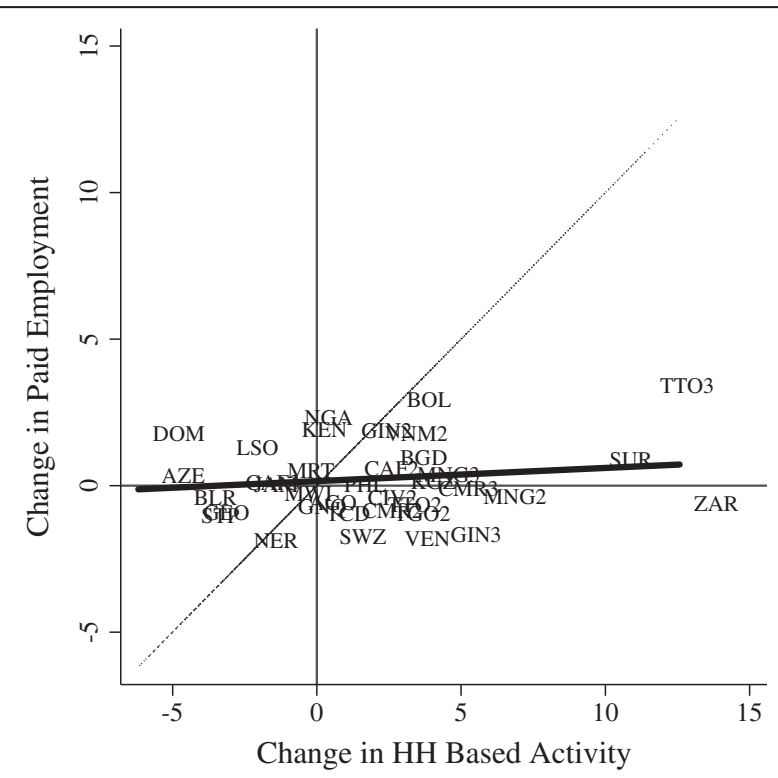

Figure 8 Relationship between changes in household based work and paid employment. Figure plots estimated change (from trend) in household based work participation at the minimum age of employment for non-hazardous work against the estimated change in paid employment participation at the same age. "Household Based Work" combines work in the family farm or business with work in unpaid household services. Fitted regression line also pictured. One outlier in change in paid employment omitted. A "2" after the country code (see Table 1) indicates the data comes from the MICS2 survey for the country ("3" for MICS3). All countries. 
In the pooled data (Table 4), we observe a decline in schooling when schooling is no longer compulsory. The decline in schooling is not matched by an increase in work, inside or outside of the home. The decline in schooling in the pooled data is concentrated in non-African countries. When we focus on Africa alone, the changes in schooling are neither substantive nor significant. Hence, in the aggregate, we do not see effects of compulsory schooling laws that match our theory.

On a by country basis (see Edmonds and Shrestha 2012), we observe statistically significant declines in schooling in Burundi, Equatorial Guinea, Ghana, South Sudan, Albania, Azerbaijan, Georgia, Guyana, Iraq, Kyrgyzstan, Macedonia, Moldova, Mongolia, Montenegro, Tajikistan, and Vietnam. Theory predicts that relaxation of binding compulsory schooling restrictions lead to increases in work. Because of missing employment data, we can examine this pattern in Burundi, Equatorial Guinea, Albania, South Sudan, Kyrgyzstan, and Mongolia. Among these countries where we observe declines in schooling when schooling is no longer compulsory, Burundi and Kyrgyzstan are the two countries where there are changes in time allocation consistent with theory. Work increases as schooling declines, although we do not find statistically significant or economically meaningful changes in paid employment in either country when schooling is no longer compulsory. Burundi is potentially the most important of these two for our analysis of the impact of minimum age of employment, because schooling is no longer compulsory at an age below the minimum age of employment, and this may bias our ability to estimate a counterfactual prevalence of child time in various activities.

There are 4 countries where we observed increases in paid employment at the minimum age. We identified these as potential type I errors, because we did not see a corresponding decline in household based activity. In fact, we observed a statistically significant increase in unpaid activities as well. All 4 countries have compulsory schooling regulations that relax at the minimum age of employment. Hence, it is possible that we are capturing the effect of compulsory schooling laws on paid employment. However, we do not observe declines in schooling in any of the four countries.

Nonetheless, we are hesitant to rule out the hypothesis that regulations are most effective when they are coordinated and that we are capturing some effect of coordinated regulation on time allocation. Even though these changes in time allocation do not conform to our prediction for binding minimum age regulation or compulsory schooling separately, the observed changes in time allocation may follow from the combination (although the lack of a change in schooling is not consistent with binding compulsory schooling regulation).

To explore this further, we consider how the impact of the minimum age of employment differs with whether compulsory schooling laws relax at the same age. Our findings in the pooled data are in Table 5. In the first row, we consider the impact of relaxing the minimum age of employment when compulsory schooling laws are not binding. We find no significant changes in time allocation for that group. In the second row, we find that relaxing the minimum age restriction at the same age as compulsory schooling is associated with an increase in paid employment. There is also a decline is school attendance which is large in magnitude, but imprecisely estimated such that we cannot reject the null of no change in school attendance at the age where both regulations relax.

Taken together, the evidence in this section suggests that the minimum age of employment is most apt to be associated with increases in paid employment when the 
laws are coordinated with compulsory schooling laws. We cannot separate whether this observation owes to selection in who has coordinated laws or an impact of both laws changing at the same time. Given that we do not generally observe statistically significant declines in school in these countries with coordinated laws, we suspect that selection is more important. Nonetheless, it is important to keep these cases in mind in contrast to all other countries where we do not find evidence of binding minimum age of employment regulation.

\section{Conclusion}

Minimum age of employment regulation is a centerpiece in anti-child labor policy, and considerable political attention has been invested in promoting these laws around the world. Minimum age regulations are designed to deter child involvement in paid employment as well as specific types of jobs, and work to change the distribution of job types by age.

In this study, we examine data from 59 countries included in the 2000 and 2005 UNICEF MICS project. We first consider how much of the variation in child engagement can be explained by age: less than one percent across the countries studied here. This observation does not inform us whether minimum age regulations influence time allocation. However, the finding that less than one percent of the variation in paid employment among children can be explained by age implies that age based regulation will have limited importance in explaining time allocation. In contrast, child invariant household characteristics that account for 63 percent of the variation in child participation in paid employment.

Not only is little of the variation in paid employment associated with age, but we also do not find evidence consistent with binding minimum age of employment regulation for any country. Binding minimum age of employment regulation shifts child labor from outside to inside the household without changing schooling. We do not see evidence consistent with this labor substitution in any country at the minimum age of employment. In fact, there is generally a positive association between changes in paid employment and work inside the household in the data. There are 4 countries where compulsory schooling laws relax at the same as the minimum age of employment and where we find evidence that could be driven by a combination of the two laws. Some

Table 5 Changes in time allocation with relaxation of minimum age restrictions by compulsory schooling status, all countries pooled

\begin{tabular}{|c|c|c|c|c|c|c|c|c|}
\hline \multicolumn{2}{|c|}{ Paid Employment } & \multirow{2}{*}{$\begin{array}{l}\text { Unpaid } \\
\text { Economic } \\
\text { Activity }\end{array}$} & \multirow{2}{*}{$\begin{array}{l}\text { Economic } \\
\text { Activity }\end{array}$} & \multirow{2}{*}{$\begin{array}{l}\text { Unpaid } \\
\text { Hh. } \\
\text { Services }\end{array}$} & \multirow{2}{*}{$\begin{array}{l}\text { Hh. } \\
\text { Based } \\
\text { EA \& } \\
\text { Services }\end{array}$} & \multirow{2}{*}{$\begin{array}{l}\text { Any } \\
\text { Work }\end{array}$} & \multirow{2}{*}{$\begin{array}{l}\text { Attend } \\
\text { School }\end{array}$} & \multirow[t]{2}{*}{ Idle } \\
\hline Base & Change & & & & & & & \\
\hline \multicolumn{9}{|c|}{ Schooling is not Compulsory at Minimum Age of Employment } \\
\hline 0.068 & -0.002 & -0.040 & -0.026 & 0.018 & -0.050 & -0.042 & 0.000 & -0.010 \\
\hline$(0.005)$ & $(0.007)$ & $(0.057)$ & $(0.059)$ & $(0.059)$ & $(0.057)$ & $(0.056)$ & $(0.039)$ & $(0.029)$ \\
\hline \multicolumn{9}{|c|}{ Schooling Stops Being Compulsory at Minimum Age of Employment } \\
\hline 0.056 & $0.018^{* *}$ & 0.011 & 0.022 & 0.084 & 0.088 & 0.082 & -0.073 & 0.028 \\
\hline (0.004) & $(0.004)$ & $(0.048)$ & $(0.047)$ & $(0.073)$ & $(0.063)$ & $(0.059)$ & $(0.061)$ & $(0.019)$ \\
\hline
\end{tabular}

Change in column variable at age of relaxation of minimum age of employment regulation. Age cell level regressions. Each cell weighted by population. All countries pooled. **significant at 5 percent. 
countries allow light work at ages below the minimum age of employment, and in one country (Trinidad and Tobago), we observe changes in time allocation that are consistent with changes in time allocation from light work regulation.

Taken together, the evidence in this paper does not suggest an influence of minimum age of employment regulation on child time allocation that is commensurate with the level of policy attention to promoting the regulation. Hence, political economy concerns about the impact of such regulations on constituencies for child labor reform are probably not of first order importance (Deopke and Zilibotti 2005). This raises the question of whether a case can be made for promoting the regulation nonetheless. First, it is important to recall that our findings are only answering the question of what would happen if minimum age of employment regulation were extended an additional year. Hence, we miss any effects of regulations that are gradual. It could be that these regulations signal to uncertain families that they cannot consider work for the child at younger ages. Relaxing the regulation has no immediate effect, but it sets the reference point for families that would otherwise be much earlier. Our design does not capture gradual effects of the regulation. It is useful to recall how little of the variation in paid employment is associated with age.

Second, our design does not capture general equilibrium effects of the regulation on the structure of employment or prices, including wages, in the overall economy. For example, if minimum age regulation raised wages (as in the Basu and Van 1998 framework), then it would eliminate motives for work compared to the counterfactual of no regulation at all. The regulation would then reduce the incidence of child labor overall, and we might not observe any discrete change in time allocation at the minimum age because the law reduces the supply of child labor. Our design cannot capture any effect of the law beyond the age where the laws are relaxed. Edmonds has argued elsewhere (Edmonds 2008) that such types of general equilibrium responses to child labor regulation are unlikely, but we cannot rule them out with our design.

Third, it may be the case that these laws provide benefits that have nothing to do with changing the time allocation of children at the minimum age. Perhaps they help establish norms over very long time horizons. Perhaps they provide tools for the legal system to go after gross violators. Perhaps they provide organizing principles for other government anti-child labor laws. There are many possible reasons, but policy should be clearer about the exact purpose and utility of minimum age of employment regulation. It is clear from the evidence herein that minimum age regulations, as currently implemented, do not generally alter child engagement in paid employment at the minimum age itself compared to a counterfactual where the minimum age was set one year later. Moreover, the evidence herein is consistent with the notion that age-based regulation is not the most natural priority of policy aimed to deter child labor given the clear dominance of child invariant, household characteristics in explaining variation in paid employment.

\section{Endnotes}

"We are grateful to Doug Miller, Doug Staiger, seminar participants at Harvard and the University of Connecticut, David Neumark, and two anonymous referees for extremely helpful comments and to Zakariah Lakel, Meagan Morrow, Yang Wei Neo, 
Dana Niu, Mary Peng, Greg O'Sullivan, Niral Shah, Connie Shang, and Amy Zhang for research assistance.

${ }^{1}$ Idleness is defined as not attending school while not working or participating in household based activities, including chores. All analysis of variance is based on a model regressing paid employment, household fixed effects, age effects, and gender for households with more than 1 child 8-14 present. Thus, all discussion of the explanatory power of age is based on the partial R2 attributable to age in the model.

${ }^{2} \mathrm{C} 138$ can be read at http://www.ilo.org/ilolex/cgi-lex/convde.pl?C138.

${ }^{3} \mathrm{C} 182$ is available from http://www.ilo.org/ilolex/cgi-lex/convde.pl?C182.

${ }^{4}$ The data are available from http://www.childinfo.org/. A few countries in the publicly available data have been excluded from our study, because they did not execute the child labor module.

${ }^{5}$ Most working children do so inside their household. In our data, children are 9 times more likely to work in the family farm or business than in paid employment. We think it is reasonable to suppose that the typical household in our data has some sort of farm or home enterprise in which children may participate.

${ }^{6}$ If there is no adult labor market and no child labor market, then there is no labor market in which to regulate the child's participation. Hence, the premise of minimum age regulation on employment outside of the child's home is that there is some functioning labor market present.

${ }^{7}$ This assumption may be inaccurate owing to school transition points or compulsory schooling laws, a subject we will return to later.

${ }^{8} \mathrm{We}$ believe the unique household identifiers in the Comoros and Cote d'Ivoire data from MICS2 are incorrect, because they are associated with implausible household sizes. We choose to leave them into the figure, because we will use their data in our later analysis (which does not depend on having the correct household identifier).

\section{Competing interests}

The IZA Journal of Labor Policy is committed to the IZA Guiding Principles of Research Integrity. The authors declare that they have observed these principles. Although both Edmonds and Shrestha wish to declare that they have served as compensated consultants for international and government agencies involved in promoting minimum age of employment regulation during the period of writing this paper although their consulting did not directly relate to minimum age of employment regulation directly.

Responsible editor: David Neumark

\section{Author details}

${ }^{1}$ Dartmouth College Department of Economics. 6106 Rockefeller Hall. Hanover, NH 03755, USA. ${ }^{2}$ MIT Department of Economics. 50 Memorial Drive, E53-393, Cambridge, MA 02142, USA.

Received: 8 August 2012 Accepted: 18 December 2012

Published: 31 December 2012

\section{References}

Banerjee AV, Duflo E (2007) The economic lives of the poor. J Econ Perspect 21(1):141-167

Basu K, Van PH (1998) The economics of child labor. Am Econ Rev 88(3):412-427

Black D, Jose G, Smith J (2007) "Evaluating the Bias of the Regression Discontinuity Design Using Experimental Data,". University of Michigan Working Paper. University of Michigan: Ann Arbor Ml

Deopke M, Zilibotti F (2005) The macroeconomics of child labor regulation. Am Econ Rev 95(5):1492-1524

Edmonds E (2008) Child Labor. In: Shultz TP, Strauss J (eds), 57th edn Handbook of Development Economics, pp 3608-3709, vol. 4. Elsevier: Amsterdam

Edmonds E, Shrestha M (2012) "The Impact of Minimum Age of Employment Regulation on Child Labor and Schooling: Evidence from UNICEF MICS Countries.". Working Paper \# 18623. National Bureau of Economic Research: Cambridge MA 
Goldin C, Katz L (2011) "Mass Secondary Schooling and the State: The Role of State Compulsion in the High School Movement,". In: Dora C, Naomi L (eds) Understanding Long-Run Economic Growth: Geography, Institutions, and the Knowledge Economy. pp 275-310. University of Chicago Press: Chicago IL

Lee D, Lemieux T (2011) "Regression discontinuity design in economics,". J Econ Lit 48(June):281-355

Lleras-Muney A (2002) Were compulsory attendance and child labor laws effective? an analysis from 1915 to 1939. J Law Econ 45(2):401-35

Moehling C (1999) State child labor laws and the decline of child labor. Explor Econ Hist 36:72-106

Oreopoulos P (2006) Estimating average and local average treatment effects of education when compulsory schooling laws really matter. Am Econ Rev 96(1):152-175

doi:10.1186/2193-9004-1-14

Cite this article as: Edmonds and Shrestha: The impact of minimum age of employment regulation on child labor and schooling*. IZA Journal of Labor Policy 2012 1:14.

Submit your manuscript to a SpringerOpen ${ }^{\circ}$ journal and benefit from:

- Convenient online submission

- Rigorous peer review

- Immediate publication on acceptance

- Open access: articles freely available online

- High visibility within the field

- Retaining the copyright to your article

Submit your next manuscript at $>$ springeropen.com 